\title{
BMJ Open Prevalence and factors associated with hypertension among adults in rural Sylhet district of Bangladesh: a cross- sectional study
}

\begin{abstract}
Rasheda Khanam, ${ }^{1}$ Salahuddin Ahmed, ${ }^{2}$ Sayedur Rahman, ${ }^{2}$ Gulam Muhammed Al Kibria, ${ }^{3}$ Jafar Raza Rizvi Syed, ${ }^{2}$ Ahad Mahmud Khan, ${ }^{2}$ Syed Mamun Ibne Moin, ${ }^{2}$ Malathi Ram, ${ }^{1}$ Dustin G Gibson (1) , ${ }^{1}$ George Pariyo, ${ }^{1}$ Abdullah H. Baqui, ${ }^{1}$ for the Projahnmo Study Group in Bangladesh
\end{abstract}

To cite: Khanam R, Ahmed S, Rahman S, et al. Prevalence and factors associated with hypertension among adults in rural Sylhet district of Bangladesh: a crosssectional study. BMJ Open 2019;9:e026722. doi:10.1136/ bmjopen-2018-026722

- Prepublication history for this paper is available online. To view these files, please visit the journal online (http://dx.doi org/10.1136/bmjopen-2018026722).

Received 16 September 2018 Revised 30 August 2019 Accepted 12 September 2019

Check for updates

(c) Author(s) (or their employer(s)) 2019. Re-use permitted under CC BY-NC. No commercial re-use. See rights and permissions. Published by BMJ.

${ }^{1}$ Department of International Health, Johns Hopkins Bloomberg School of Public Health, Baltimore, MD, United States

${ }^{2} J o h n s$ Hopkins University, Dhaka, Bangladesh

${ }^{3}$ Department of Epidemiology and Public Health, University of Maryland School of Medicine, Baltimore, Maryland, USA

Correspondence to Dr Rasheda Khanam; rkhanam1@jhu.edu

\section{ABSTRACT}

Objectives Low-income and middle-income countries are undergoing epidemiological transition, however, progression is varied. Bangladesh is simultaneously experiencing continuing burden of communicable diseases and emerging burden of non-communicable diseases (NCDs). For effective use of limited resources, an increased understanding of the shifting burden and better characterisation of risk factors of NCDs, including hypertension is needed. This study provides data on prevalence and factors associated with hypertension among males and females 35 years and older in rural Bangladesh.

Methods This is a population-based cross-sectional study conducted in Zakiganj and Kanaighat subdistricts of Sylhet district of Bangladesh. Blood pressure was measured and data on risk factors were collected using STEPS instrument from 864 males and 946 females aged 35 years and older between August 2017 and January 2018. Individuals with systolic blood pressure of $\geq 140 \mathrm{~mm} \mathrm{Hg}$ or diastolic blood pressure of $\geq 90 \mathrm{~mm} \mathrm{Hg}$ or taking antihypertensive drugs were considered hypertensive. Bivariate and multivariate analyses were performed to identify factors associated with hypertension.

Results The prevalence of hypertension was 18.8\% (95\% Cl 16.3 to 21.5 ) and $18.7 \%$ (95\% Cl 16.3 to 21.3 ) in adult males and females, respectively. Among those who were hypertensive, the prevalence of controlled, uncontrolled and unaware/newly identified hypertension was $23.5 \%$, $25.9 \%$ and $50.6 \%$, respectively among males and $38.4 \%$, $22.6 \%$ and $39.0 \%$, respectively among females. Another $22.7 \%$ males and $17.8 \%$ females had prehypertension. Increasing age and higher waist circumference $(\geq 90 \mathrm{~cm}$ for males and $\geq 80 \mathrm{~cm}$ for females) were positively associated with hypertension both in males (OR 4.0, 95\% $\mathrm{Cl} 2.5$ to 6.4) and females (OR 2.8, 95\% Cl 2.0 to 4.1$)$.

Conclusions In view of the high burden of hypertension and prehypertension, a context-specific scalable public health programme including behaviour change communications, particularly to increase physical activity and consumption of healthy diet, as well as identification and management of hypertension needs to be developed and implemented.

\section{Strengths and limitations of this study}

- The study provides primary data on prevalence and associated factors of hypertension for adult males and females from community-based samples of a low resource setting.

- We used standard and validated STEPS instrument which is used widely allowing comparison of our data with data from other studies.

- The cross-sectional nature of the study limits the ability to establish causal relationship between the observed factors and hypertension.

- We could not measure all the potential risk factors for hypertension which could have enhanced the interpretation

\section{INTRODUCTION}

Each year an estimated 41 million people die from non-communicable diseases (NCDs) accounting for about $70 \%$ of all deaths globally. ${ }^{1}$ Hypertension is one of the most common NCDs. According to the Global Burden of Disease (GBD) reports, between 1990 and 2010, there has been a shift in disease burden from communicable diseases to NCDs. ${ }^{12}$ This was most notable in South Asia and sub-Saharan Africa regions, where a substantial proportion of the world's population reside and where high blood pressure (BP) has had a particularly large effect on disease burden. ${ }^{2}$ Globally, high BP was the fourth leading risk factor for GBD in 1990, as quantified by disability-adjusted life years; it ranked as the leading risk factor in $2010{ }^{2}$ About one out of four adults around the world have hypertension and it is projected to increase to $29.2 \%$ by 2025 , which will be $>1.5$ billion people worldwide. ${ }^{3-5}$

Uncontrolled hypertension increases the risks of cardiovascular disease, strokes and 
end-stage renal failure. ${ }^{6}$ It accounts for about $45 \%$ of deaths due to ischaemic heart disease and $52 \%$ of deaths due to stroke. ${ }^{6}$ Older age, overweight/obesity, unhealthy diet, lack of physical exercise, smoking tobacco products and family history of hypertension are major risk factors for hypertension. ${ }^{78}$

The prevalence of hypertension is increasing, primarily in low-income and middle-income countries (LMICs) and remain steady or decreasing in high-income countries. ${ }^{3}$ In South Asia, the prevalence of hypertension is approximately $33 \%$ among people aged 18 years and older with a secular trend documenting that the burden of hypertension is increasing over time. ${ }^{9}$ South Asia region accounts for $23 \%$ (or an estimated 258 million) of global hypertension burden. ${ }^{9}$ An increase in hypertension prevalence in South Asia including Bangladesh could be attributed largely to modifiable behavioural risk factors such as unhealthy diet, sedentary lifestyle, excess weight, tobacco consumption, alcohol abuse and chronic stress including ageing and urbanisation. ${ }^{10-12}$

Bangladesh, like many other LMICs, is undergoing an epidemiological transition and an increased understanding of the burden and risk factors of hypertension is necessary to combat the increasing burden. ${ }^{13}$ A nationally representative survey conducted in 2011 (Bangladesh Demographic and Health Survey 2011 (BDHS-2011)) suggests that the prevalence of hypertension including undiagnosed and uncontrolled hypertension in Bangladeshi adults is high. ${ }^{14-18}$ However, the available data are not adequate to provide regional-level or district-level estimates. We have conducted this study among adults 35 years and older in a rural district of Bangladesh where we have been working for about two decades to develop and implement a scalable intervention for hypertension.

\section{METHODS}

\section{Study design and setting}

This was a population-based cross-sectional study conducted between August 2017 and January 2018 in an established field research site in Zakiganj and Kanaighat subdistricts of Sylhet district of Bangladesh. The site is maintained by a research partnership of the Johns Hopkins University, Baltimore, Maryland, USA, the Bangladesh Ministry of Health and Family Welfare and Bangladeshi non-governmental organisations. The study site is located in the north-east part of Bangladesh adjacent to the Indian states of Assam and Meghalaya, about $300 \mathrm{~km}$ away from Dhaka, the capital city of Bangladesh. Every village and household in the study area are numbered. We conduct periodic census of the study area. We also maintain a surveillance through two-monthly home visits to update vital events (births, deaths and movements) in women of childbearing age and $<5$ children, ${ }^{19-21}$ but do not update adult population. We used 2016 census database to select the study sample.

\section{Sample size}

Sample size was estimated to measure the prevalence of hypertension separately for adult males and females 35 years and older in the study population. Conservatively assuming a hypertension prevalence of $10 \%$ in both males and females, a $\pm 2 \%$ precision and a significance level of $5 \%$, the estimated sample size was 865 in each group. Assuming a $15 \%$ refusal or absence, we selected 1020 individuals in each group. This sample size allows us to detect a 5\% difference in the prevalence of hypertension between males and females.

\section{Study population and implementation}

Individuals, either a male or female aged 35 years and older were eligible to participate in the study. Pregnant women were excluded. We recruited the study participants from the database using computer-generated random numbers. They were visited in their homes by trained community health workers (CHWs) with a minimum of 10th grade education, who were already collecting routine surveillance and other study-specific data, including BP measurement of pregnant women. ${ }^{22} 23$ Given cultural sensitivities, two male CHWs were recruited to collect data from male participants. All CHWs received study-specific training.

On obtaining informed consent, CHWs administered an adapted version of the WHO's expanded STEP instrument at the participant's home. ${ }^{24} 25$ The instrument contained questions on NCD behavioural risk factors, including dietary habit, tobacco consumption and physical activity. Data on other covariates (eg, household socioeconomic status, education, occupation) were collected.

After completing the household survey, CHWs measured $\mathrm{BP}$ in $\mathrm{mm} \mathrm{Hg}$ using digital $\mathrm{BP}$ machine (OMRON 5 Series, model: BP742N). The digital machines were calibrated fortnightly by a physician against a gold standard mercury sphygmomanometer.

We measured both systolic BP (SBP) and diastolic BP (DBP) three times at approximately 10 min intervals between measurements. ${ }^{16}$ All measurements were recorded in a data form and the average of the last two measurements were used for this analysis. During measurements, the study participant remained seated with legs uncrossed and back and arm supported. We used two different cuff sizes based on mid-upper arm circumference (MUAC) measurement. For participants with a MUAC of $<22 \mathrm{~cm}$, we used small cuff and for those with a MUAC of $>22 \mathrm{~cm}$, we used a medium cuff. The cuff was placed above the left elbow at the level of chest. In addition, CHWs obtained measurements of weight (in $\mathrm{kg}$ ), height (in $\mathrm{cm}$ ), waist circumference (in $\mathrm{cm}$ ), hip circumference (in $\mathrm{cm}$ ) and MUAC (in $\mathrm{cm}$ ) of the study participants using standardised methods.

\section{Measurements}

BP was classified as normal, prehypertension or hypertension, based on criteria used in the WHO-International Society of Hypertension (WHO-ISH) ${ }^{26}$ A participant was 
considered to have normal BP if SBP was $<120 \mathrm{~mm} \mathrm{Hg}$ and the DBP was $<80 \mathrm{~mm} \mathrm{Hg}$ and not taking antihypertensive drugs. An SBP of $120-139 \mathrm{~mm} \mathrm{Hg}$ or a DBP of $80-89 \mathrm{~mm}$ $\mathrm{Hg}$ with no history of taking antihypertensive medication during survey was classified as prehypertension. ${ }^{27} \mathrm{~A}$ participant was considered having hypertension if the SBP was $\geq 140 \mathrm{~mm} \mathrm{Hg}$ or DBP was $\geq 90 \mathrm{~mm} \mathrm{Hg}$ or the BP was below these cut-offs, but the study participant reported taking antihypertensive medication. ${ }^{16}$ Controlled hypertension was defined as an $\mathrm{SBP}<140 \mathrm{~mm} \mathrm{Hg}$ and a DBP $<90 \mathrm{~mm} \mathrm{Hg}$ and reported use of antihypertensive medication during survey. ${ }^{16}$ An SBP of $\geq 140 \mathrm{~mm} \mathrm{Hg}$ or a DBP $\geq 90 \mathrm{~mm} \mathrm{Hg}$ in a study participant taking antihypertensive medication was considered as uncontrolled hypertension. An individual with $\mathrm{SBP} \geq 140 \mathrm{~mm} \mathrm{Hg}$ or $\mathrm{DBP} \geq 90 \mathrm{~mm} \mathrm{Hg}$ with no history of taking antihypertensive medication was considered as newly identified or unaware of hypertension. ${ }^{28} 29$ The participants with high measured BP were referred to the hospital for further evaluation and care.

Participants' were categorised based on age into four groups (35-44, 45-54, 55-64 and $\geq 65$ years). We calculated body mass index (BMI) as the ratio of weight in kilograms to height in metres squared $\left(\mathrm{kg} / \mathrm{m}^{2}\right)$ and categorised using the WHO-recommended cut-off points: underweight $\left(<18.5 \mathrm{~kg} / \mathrm{m}^{2}\right)$, normal $\left(18.5-24.9 \mathrm{~kg} / \mathrm{m}^{2}\right)$ and obese/overweight $\left(\geq 25.0 \mathrm{~kg} / \mathrm{m}^{2}\right) .{ }^{30}$ We categorised waist circumference into low risk $(<90 \mathrm{~cm}$ for males and $<80 \mathrm{~cm}$ for females) and high risk ( $\geq 90 \mathrm{~cm}$ for males and $\geq 80 \mathrm{~cm}$ for females). We created a household wealth score based on type of housing, source of drinking water, type of toilet, availability of electricity and household possessions as a measure of household economic status, using the Principal Component Analysis. ${ }^{31} 32$ The wealth index is a composite measure of a household's cumulative wealth that places individual household on a continuous scale of relative wealth. We divided the households into wealth tertiles.

We used STEPS instrument to collect data on risk and protective factors. ${ }^{33}$ The data on fruits and vegetables intake were combined and categorised into $<2$ servings per day, 2-4 servings per day and $\geq 5$ servings per day. Participants were defined as a current smoker if they reported smoking cigarettes, cigars or pipes during the survey. Similarly, participants were defined as a current smokeless tobacco user if reported using smokeless tobacco products such as snuff, chewing tobacco leaf, goul, noshi or zarda at the time of the survey. We collected data on physical activity (PA) across all domains including work, transportation (walking/biking) and leisure-time/ recreational activity. Data on time spent on PA were converted into minutes per week and then we calculated metabolic equivalent task (MET)-min per week for all activities combined. ${ }^{34}$ According to standard classification, a MET-min of $<600$ per week is classified as low PA, 600-3000 MET-min is considered as moderate PA and $>3000$ MET-min is considered as high PA. In our population, there was none with high PA. Based on distribution of MET-min, we have categorised our population into very low PA (<300 MET-min/week), low PA (300 to $<600 \mathrm{MET}-\mathrm{min} /$ week) and moderate PA (>600 MET-min/ week).

\section{Data analysis}

We presented per cent distribution of selected sociodemographic and other factors including median and IQR for continuous variables for the total sample as well as separately for males and females. We calculated the prevalence and 95\% CIs of hypertension, prehypertension, controlled, uncontrolled and unaware or newly identified hypertension using WHO-ISH guidelines. ${ }^{26}$ Bivariate and multivariable logistic regression were used to identify factors significantly associated with hypertension separately for males and females. First, we conducted bivariate logistic regression analysis. Variables with a p value of $<0.05$ in the bivariate analyses were included in the multivariable logistic regression model. In addition, we have added a few variables (smoking, consumption of fruits and vegetables and physical activity) as a priori even if those variables were not statistically associated in bivariate analysis because these variables have been shown to be associated with hypertension and there is biological basis for it. Data were analysed using Stata V.15 (StataCorp 2015).

\section{Patient and public involvement}

Patients or public were not involved in the design of the study. We are yet to disseminate the results.

\section{RESULTS}

We approached 1020 males and 1019 females aged 35 years or older (total of 2039) for study participation. Among the 1020 males, 29 (2.8\%) refused participation, $49(4.8 \%)$ were absent, $48(4.7 \%)$ migrated out, $2(<1 \%)$ had incomplete data, and $28(2.7 \%)$ died. Among the 1019 females, $7(0.7 \%)$ refused, $7(0.7 \%)$ were absent, 28 (2.7\%) migrated out, $14(1.4 \%)$ died, $3(<1 \%)$ had incomplete data, and $14(1.4 \%)$ were excluded because they were pregnant. Of the 1810 participants who completed the survey, 864 were males and 946 were females. Distributions of sociodemographic and lifestyle characteristics of males, females and all participants are presented in table 1 .

The median ages of male and female participants were 50 (IQR 42-60) years and 47 (IQR 40-57) years, respectively. The median BMI of males and females were 20.1 (IQR 18.2-22.5) and 20.5 (IQR 18.0-23.3) kg/ $\mathrm{m}^{2}$, respectively. Among females, $16.9 \%$ were overweight/obese and $42.5 \%$ had high waist circumference $(\geq 80 \mathrm{~cm})$. Majority of the males $(63.2 \%)$ reported smoking currently compared with $3.8 \%$ of the females who did so. About $14.5 \%$ males and $10.5 \%$ females reported intake of $\geq 5$ servings of fruits and vegetables per day. Majority of the males (57.8\%) and most females $(93.7 \%)$ reported very low PA (table 1 ).

The prevalence and $95 \%$ CI of hypertension was $18.8 \%$ (16.3 to 21.5 ) in males and $18.7 \%$ (16.3 to 21.3 ) in 
Open access

Table 1 Sociodemographic and lifestyle characteristics among adult males and females in Sylhet district of Bangladesh

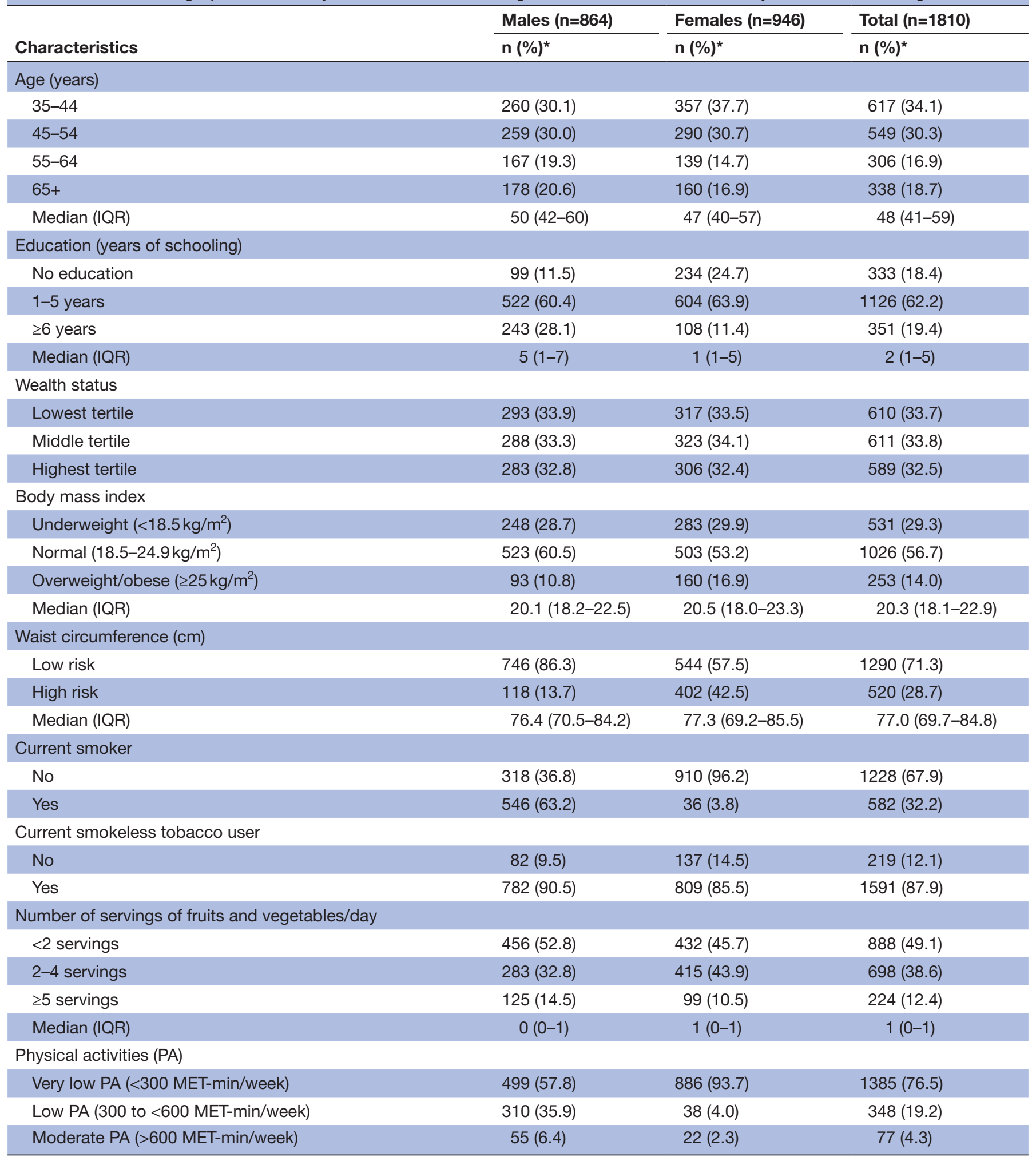

${ }^{*}$ Column percentage.

†For males, low risk is $<90 \mathrm{~cm}$ and high risk is $\geq 90 \mathrm{~cm}$ and for females, low risk is $<80 \mathrm{~cm}$ and high risk is $\geq 80 \mathrm{~cm}$. MET, metabolic equivalent task.

females (table 2). Among those with hypertension, the prevalence of controlled, uncontrolled and unaware/ newly identified hypertension was $23.5 \%, 25.9 \%$ and
$50.6 \%$, respectively among males and $38.4 \%, 22.6 \%$ and $39.0 \%$, respectively among females (table 2 and figure 1 ). 
Table 2 Distribution of blood pressure levels in males and females in rural Bangladesh

\begin{tabular}{|c|c|c|c|}
\hline & $\begin{array}{l}\text { Males } \\
\mathrm{n}=864\end{array}$ & $\begin{array}{l}\text { Females } \\
\mathrm{n}=946\end{array}$ & $\begin{array}{l}\text { Total } \\
n=1810\end{array}$ \\
\hline Blood pressure categories & $\%, 95 \% \mathrm{Cl}$ & $\%, 95 \% \mathrm{Cl}$ & $\%, 95 \% \mathrm{Cl}$ \\
\hline Prehypertension† & $22.7,20.0$ to 25.6 & $17.8,15.4$ to 20.3 & $20.1,18.3$ to 22.0 \\
\hline Hypertension $\ddagger$ & $18.8,16.3$ to 21.5 & $18.7,16.3$ to 21.3 & $18.7,17.0$ to 20.6 \\
\hline Uncontrolled & $25.9,19.4$ to 33.4 & $22.6,16.7$ to 29.5 & $24.2,19.7$ to 29.1 \\
\hline Newly identified ${ }^{\star \star}$ & $50.6,42.7$ to 58.6 & $39.0,31.8$ to 46.6 & $44.5,39.2$ to 50.0 \\
\hline
\end{tabular}

*SBP $<120 \mathrm{~mm} \mathrm{Hg}$ and DBP $<80 \mathrm{~mm} \mathrm{Hg}$ and not taking antihypertensive medication.

†SBP $120-139 \mathrm{~mm} \mathrm{Hg}$ or DBP $80-89 \mathrm{~mm} \mathrm{Hg}$ and not taking antihypertensive medication.

$\ddagger S B P \geq 140 \mathrm{~mm} \mathrm{Hg}$ or DBP $\geq 90 \mathrm{~mm} \mathrm{Hg}$ or taking antihypertensive medication.

$\S S B P<140 \mathrm{~mm} \mathrm{Hg}$ and DBP $<90 \mathrm{~mm} \mathrm{Hg}$ but taking antihypertensive medication.

ISBP $\geq 140 \mathrm{~mm} \mathrm{Hg}$ or DBP $\geq 90 \mathrm{~mm} \mathrm{Hg}$ and taking antihypertensive medication.

${ }^{*} \mathrm{SBP} \geq 140 \mathrm{~mm} \mathrm{Hg}$ or DBP $\geq 90 \mathrm{~mm} \mathrm{Hg}$ and not taking antihypertensive medication.

DBP, diastolic blood pressure; SBP, systolic blood pressure.

Another $22.7 \%$ of the males and $17.8 \%$ of the females were prehypertensive.

Simple and multivariable logistic regression analyses to investigate factors associated with hypertension are presented in table 3. In unadjusted logistic regression, the risk of hypertension was higher among those older than 45 years, overweight/obese and who had high waist circumference ( $\geq 90 \mathrm{~cm}$ for males and $\geq 80 \mathrm{~cm}$ for females). The odds of hypertension were lower in both males and
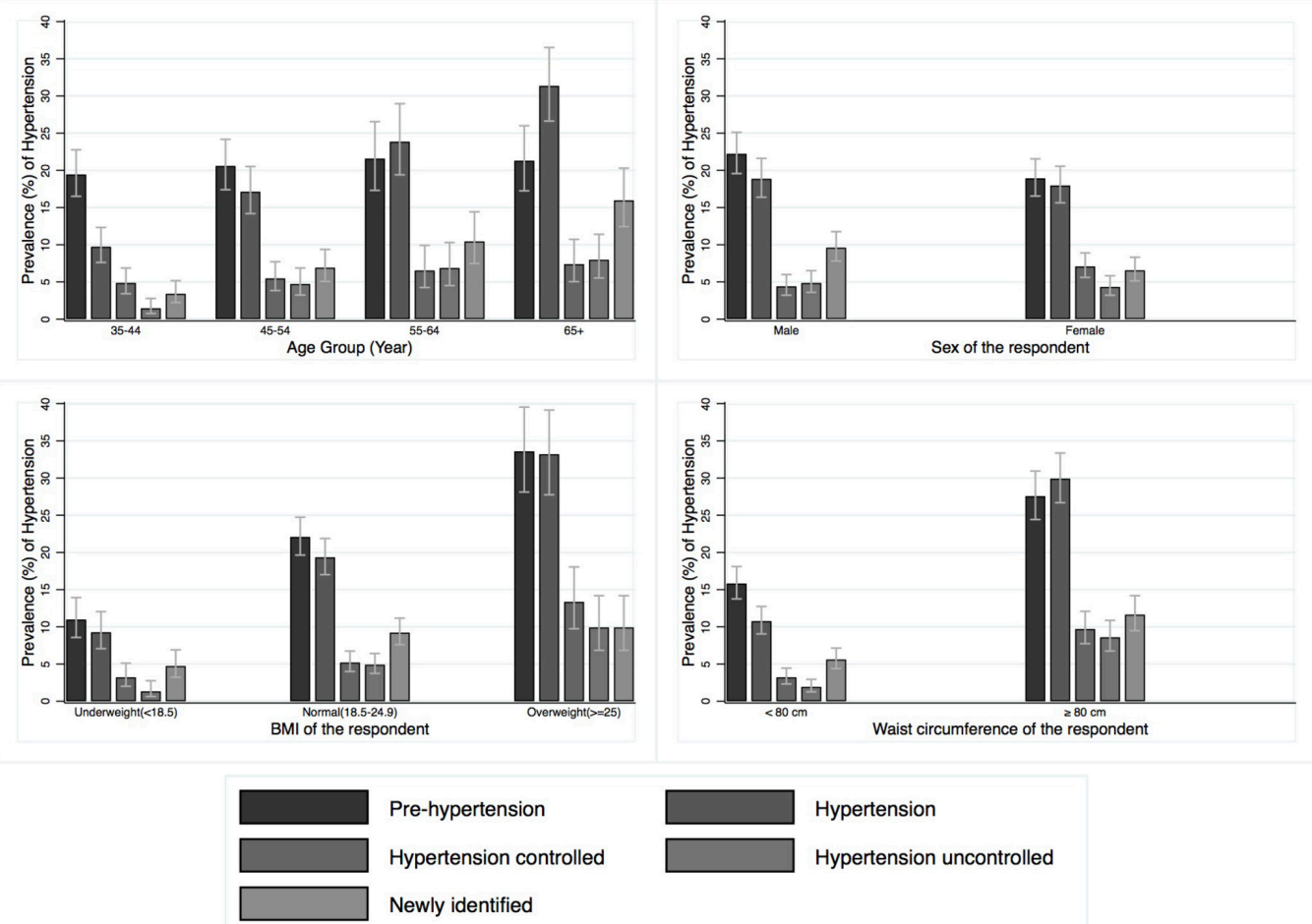

Figure 1 Distribution of blood pressure categories by age, sex, body mass index (BMI) and waist circumference, Sylhet, Bangladesh. females who were underweight. Among males, those who belonged to the highest wealth tertile and among females who belonged to the middle and highest wealth tertiles had significantly higher odds of hypertension in unadjusted logistic regression. Among males, compared with those with very low PA, those with low and moderate PA had lower prevalence of hypertension (table 3 ).

In the adjusted logistic regression model, we included waist circumference but not BMI because they were highly 
Table 3 Factors associated with hypertension among males and females in rural Bangladesh

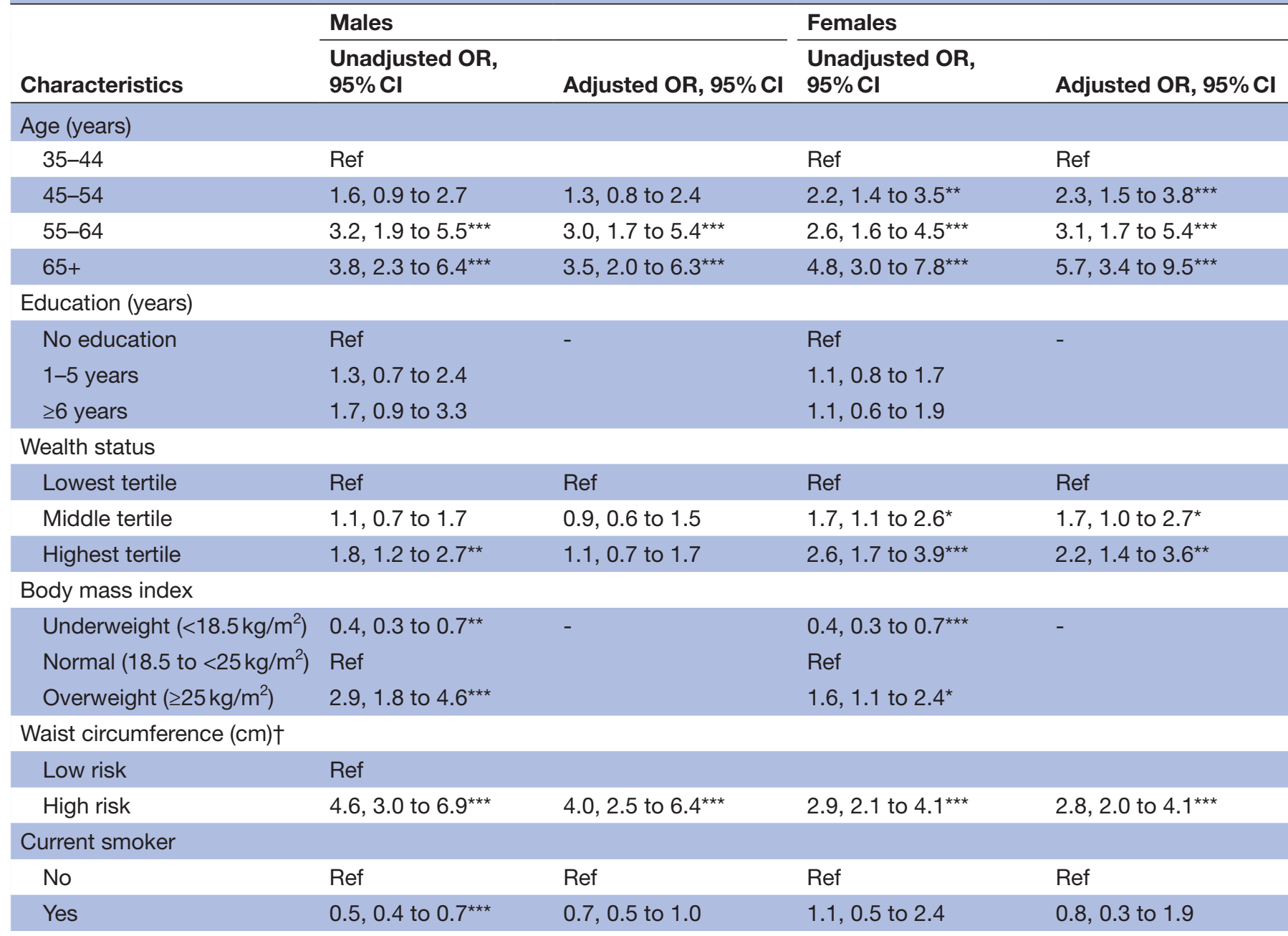

Current smokeless tobacco users

\begin{tabular}{|c|c|c|c|c|}
\hline No & Ref & Ref & Ref & Ref \\
\hline Yes & $0.5,0.3$ to $0.9^{\star}$ & $0.6,0.4$ to 1.1 & $1.0,0.6$ to 1.7 & $0.9,0.5$ to 1.5 \\
\hline \multicolumn{5}{|l|}{$\begin{array}{l}\text { Number of fruits and } \\
\text { vegetables servings/day }\end{array}$} \\
\hline$<2$ servings & Ref & Ref & Ref & Ref \\
\hline 2-4 servings & $1.3,0.9$ to 1.9 & $1.1,0.7$ to 1.6 & $1.0,0.7$ to 1.4 & $0.8,0.5$ to 1.2 \\
\hline \multicolumn{5}{|l|}{ Physical activities (PA) } \\
\hline $\begin{array}{l}\text { Very low PA (<300 MET-min/ } \\
\text { week) }\end{array}$ & Ref & Ref & Ref & Ref \\
\hline $\begin{array}{l}\text { Low PA ( } 300 \text { to <600 MET- } \\
\mathrm{min} / \text { week) }\end{array}$ & $0.4,0.2$ to $0.6^{\star \star \star}$ & $0.6,0.4$ to $1.0^{*}$ & $0.5,0.2$ to 1.4 & $0.5,0.2$ to 1.6 \\
\hline
\end{tabular}

${ }^{*} \mathrm{P}<0.05 ;{ }^{* *} \mathrm{p}<0.01 ;{ }^{* * *} \mathrm{p}<0.001$.

†For males, low risk is $<90 \mathrm{~cm}$ and high risk is $\geq 90 \mathrm{~cm}$ and for females, low risk is $<80 \mathrm{~cm}$ and high risk is $\geq 80 \mathrm{~cm}$.

MET, metabolic equivalent task.

correlated $(\mathrm{r}=0.68)$. In the adjusted analysis, among males, age older than 45 years and waist circumference $\geq 90 \mathrm{~cm}$ was positively and reported low and moderate PA were inversely related to risk of hypertension (table 3 ). Among females, older age, higher socioeconomic status and waist circumference $\geq 80 \mathrm{~cm}$ was positively related to 
risk of hypertension (table 3). The odds of hypertension were increasing as the age was increasing both in males (45-55 years: adjusted OR (aOR) $1.3,95 \%$ CI 0.8 to 2.4; 55-64 years: aOR $3.0,95 \%$ CI 1.7 to $5.4,65+$ years: aOR 3.5 , $95 \%$ CI 2.0 to 6.3 ) and in females (45-55 years: aOR 2.3, 95\% CI 1.5 to $3.8,55-64$ years: aOR 3.1, 95\% CI 1.7 to 5.4 , 65 + years: aOR 5.7, 95\% CI 3.4 to 9.5$)$. The odds of hypertension were fourfolds higher among males (aOR 4.0, $95 \%$ CI 2.5 to 6.4 ) and threefolds higher among females (aOR 2.8, 95\% CI 2.0to 4.1) with high waist circumference ( $\geq 90 \mathrm{~cm}$ in males and $\geq 80 \mathrm{~cm}$ in females). In a subsequent adjusted model, we replaced waist circumference by BMI; overweight/obese was significantly associated with greater odds of hypertension in both males (aOR $3.1,95 \%$ CI 1.8 to 5.3 ) and females (aOR $1.9,95 \%$ CI 1.2 to 2.9) (data not shown).

\section{DISCUSSION}

In this population-based cross-sectional study in rural Bangladesh, the prevalence of hypertension was high among both males $(18.8 \%)$ and females $(18.7 \%)$. The prevalence of prehypertension was also high at $22.7 \%$ among males and $17.8 \%$ among females. Among those who had hypertension, more than half of the males and about a third of the females were not aware of it. Additionally, about a quarter of the hypertensive males and females had uncontrolled hypertension. Compared with males, a higher proportion of females had controlled hypertension.

The data on prevalence of and risk factors for hypertension in Bangladesh are limited. The BDHS-2011 measured BP in a nationally representative sample of adult males and females. ${ }^{16}$ The BDHS estimates of hypertension prevalence for Sylhet division were similar to our finding among males but was higher $(25.2 \%)$ among females. However, the BDHS Sylhet prevalence rate for females was based on 232 women with a wide 95\% CI (19.6 to 31.1). BDHS documented a substantial urban versus rural and regional variations. The urban sample had a much higher prevalence than the rural sample $(40.2 \%$ vs 29.4\%). Among eight divisions (regions) of Bangladesh, Sylhet division where the current study was conducted, had the lowest prevalence $(25.2 \%) .{ }^{16}$ Our findings of prevalence of hypertension is similar in females $(18.4 \%$ vs $18.7 \%$ ) but higher in males $(13.5 \%$ vs $18.8 \%)$ than in a study conducted among adults 25 years and older in 2005 in three rural areas of Bangladesh. ${ }^{35}$

Our findings of positive associations between hypertension and potential risk factors such as age, BMI and waist circumference are consistent with several studies from Bangladesh and elsewhere. ${ }^{17} 1836$ A dose-response relationship was observed between the risk of hypertension and age, the risk increased with the increase of age; highest risk was observed in the oldest age groups among both males and females. ${ }^{1837}$

High BMI is an established risk factor for hypertension $^{15}$; several studies found that overweight/obesity had the strongest association with hypertension. ${ }^{35} 3839$ Body weight is the balance between consumption and expenditure of energy. One would expect higher calorie consumption among higher SES group. Adult males and females with a higher waist circumference had fourfold and threefold higher risks of hypertension, respectively. Both BMI and waist circumference are established risk factors for hypertension. In our study, we analysed them separately but presented waist circumference data instead of BMI because several studies suggested that abdominal fat deposition is generally a stronger predictor of hypertension than BMI-based association. ${ }^{40}$ Moreover, we chose waist circumference in our model instead of BMI because it can be easily measured, and programme can use it for screening provided training is adequate.

Compared with those who belonged to the poorest wealth group, we observed about a twofold higher risk of hypertension among females but not among males who belonged to higher wealth groups. The association of SES with hypertension is not consistent across studies; some studies observed higher rate of hypertension among higher socioeconomic group and yet, other studies observed higher rate among the poor. ${ }^{35} 4243 \mathrm{~A}$ recent review reported an overall increased risk of hypertension among the lowest SES, particularly in high-income countries. $^{43}$

Association between PA and risk of hypertension are well documented. Interventional studies showed beneficial effects of PA on BP reduction. ${ }^{44}{ }^{45}$ Recreational PA is uncommon in our population $(<1 \%)$. We observed a lower risk among males who reported PA for $\geq 300$ MET-min per week. Compared with those with very low PA, the odds of having hypertension was $40.0 \%$ and $70.0 \%$ less among males who had reported low and moderate PA, respectively.

We did not see a protective effect of fruit or vegetable consumptions on hypertension in our population. In this poor agrarian community, most people consume vegetables every day, the quantity might be low. Fruit consumption is low among rural Bangladeshi people. Seasonal fruits are grown in abundance but are not popular because people do not consider them as good fruit. ${ }^{46}$ Imported fruits are costly and remain unaffordable to many people leading to a very low consumption of fruit. ${ }^{46}$ The benefit of fruits and vegetable consumption is primarily through increased intake of potassium. ${ }^{478}$ All vegetables may not contain high level of potassium and washing, and cooking may reduce potassium level. ${ }^{49}$ In this study, we did not see a higher risk among smokers. Not seeing a benefit of fruit and vegetable consumption or not seeing an increased risk among smokers could be due to reverse causation, that is, those with hypertension might have modified their behaviour but that is unlikely because about half of those hypertensive were newly diagnosed.

The study has several limitations. The cross-sectional nature of the study limits the ability to establish causal relationship between the observed risk factors and hypertension. Also, the study was conducted in one region of 
Bangladesh and may not be generalisable for the entire country. The sample size is small, which limited risk factor analysis. We did not collect data on a number of important factors that may be associated with hypertension including family history, life style and salt intake. We defined hypertension by measuring BP levels at the field level, not in a clinic setting. However, our workers were adequately trained and had years of experience measuring BP in the field setting. We calibrated the BP machines fortnightly against mercury sphygmomanometer. This survey used standard and pretested STEPs questionnaire to collect data from study participants which is used widely allowing comparison of our data with data from other studies.

Our finding of high rates of hypertension in this rural area is important because the risk of CVDs is about 16 folds higher among those with hypertension compared with those with an SBP of $<115 \mathrm{~mm} \mathrm{Hg}$ and a DBP of $<75$ $\mathrm{mm} \mathrm{Hg} .{ }^{50}$ However, the risk of CVDs is higher for all individuals with an $\mathrm{SBP}>115 \mathrm{~mm} \mathrm{Hg}$ or a $\mathrm{DBP}$ of $>75 \mathrm{~mm}$ Hg. ${ }^{50-52}$ For every $10 \mathrm{~mm}$ increase in BP, the risk almost doubles. Although the risk is lower in the so-called normal BP groups compared with those with hypertension, since there are many more individuals in these $\mathrm{BP}$ categories, the burden of CVD related to hypertension among them is substantial. Therefore, efforts need to be made to identify and control hypertension and adopt strategies to reduce $\mathrm{BP}$ of the entire population and prevent rise of $\mathrm{BP}$ with age.

Our results show a high prevalence of hypertension and prehypertension in the surveyed population. In addition, high prevalence of newly diagnosed and uncontrolled hypertension despite the availability of low cost and safe drugs for hypertension is a major public health concern. Apart from age, the most important risk factor of hypertension is behavioural and potentially modifiable. For example, inappropriate diet and inadequate physical inactivity lead to overweight/obesity, raises BP and increases unfavourable blood lipids. These factors together with tobacco use, explain at least $75 \%$ of cardiovascular disease. Addressing behavioural risk factors, particularly unhealthy diet and physical inactivity can prevent hypertension. Salt reduction initiatives can make a major contribution to prevention and control of high BP. However, vertical programme focusing on hypertension control alone are not cost-effective. ${ }^{53}$ Integrated context-specific programme including behaviour change and identification and management of hypertension needs to be designed and implemented at scale through a primary healthcare approach. That will be an affordable and sustainable approach for countries to tackle the increasing burden of hypertension. ${ }^{53}$

Acknowledgements The authors would like to thank the Projahnmo study team for their enthusiastic hard work to implement the study in the field. The authors would like to thank the study participants for their participation in the study. The authors would also like to thank Allysha Chowdhury for her contribution as a student investigator during implementation of the study in the field.
Contributors The study was designed, and analysis was conceptualised by RK and AB. RK, AB, SA, SR and AMK implemented the study. SJRR and SMIM managed the data. RK, GMAIK and MR conducted data analysis. GP and DG contributed to the study design and data interpretation. RK drafted the manuscript with support from AB. All authors reviewed and provided feedback on the draft and approved the final manuscript.

Funding The authors have not declared a specific grant for this research from any funding agency in the public, commercial or not-for-profit sectors.

Competing interests None declared.

Patient consent for publication Not required.

Ethics approval This study was approved by the National Research Ethics Committee of the Bangladesh Medical Research Council (BMRC; Ref: BMRC/ NREC/2016-2019/248) and the Institutional Review Board (IRB) of the Johns Hopkins Bloomberg School of Public Health, USA (IRB No: 00007815).

Provenance and peer review Not commissioned; externally peer reviewed.

Data availability statement All data relevant to the study are included in the article or uploaded as supplementary information.

Open access This is an open access article distributed in accordance with the Creative Commons Attribution Non Commercial (CC BY-NC 4.0) license, which permits others to distribute, remix, adapt, build upon this work non-commercially, and license their derivative works on different terms, provided the original work is properly cited, appropriate credit is given, any changes made indicated, and the use is non-commercial. See: http://creativecommons.org/licenses/by-nc/4.0/.

\section{ORCID iD}

Dustin G Gibson http://orcid.org/0000-0002-9073-3376

\section{REFERENCES}

1 Forouzanfar MH, Afshin A, Alexander LT, et al. Global, regional, and national comparative risk assessment of 79 behavioural, environmental and occupational, and metabolic risks or clusters of risks, 1990-2015: a systematic analysis for the global burden of disease study 2015. Lancet 2016;388:1659-724.

2 Bromfield S, Muntner P. High blood pressure: the leading global burden of disease risk factor and the need for worldwide prevention programs. Curr Hypertens Rep 2013;15:134-6.

3 Lim SS, Vos T, Flaxman AD, et al. A comparative risk assessment of burden of disease and injury attributable to 67 risk factors and risk factor clusters in 21 regions, 1990-2010: a systematic analysis for the global burden of disease study 2010. Lancet 2012;380:2224-60.

4 Kearney PM, Whelton M, Reynolds K, et al. Global burden of hypertension: analysis of worldwide data. Lancet 2005;365:217-23.

5 O'Brien E. The Lancet Commission on hypertension: addressing the global burden of raised blood pressure on current and future generations. J Clin Hypertens 2017;19:564-8.

6 WHO. A global brief on hypertension: silent killer, global public health crisis. WHO/DCO/WHD/2013.2, 2013.

7 Alwan A. Global status report on noncommunicable diseases 2010. World Health Organization, 2011.

8 Koly KN, Biswas T, Islam A. Increasing prevalence of hypertension in Bangladesh: a review. Cardiovascular Journal 2015;8:59-64.

9 Zhou B, Bentham J, Di Cesare M, et al. Worldwide trends in blood pressure from 1975 to 2015: a pooled analysis of 1479 populationbased measurement studies with $19 \cdot 1$ million participants. Lancet 2017;389:37-55.

10 Mendis S. Hypertension: a silent contributor to the global cardiovascular epidemic. Reg Health Forum 2013;17:1-6.

11 Virdis A, Giannarelli C, Neves MF, Fritsch Neves M, et al. Cigarette smoking and hypertension. Curr Pharm Des 2010;16:2518-25.

12 Neupane D, McLachlan CS, Sharma R, et al. Prevalence of hypertension in member countries of South Asian association for regional cooperation (SAARC). Medicine 2014;93:e74.

13 Ahsan Karar Z, Alam N, Kim Streatfield P. Epidemiological transition in rural Bangladesh, 1986-2006. Glob Health Action 2009;2:1904.

14 Islam FMA, Bhuiyan A, Chakrabarti R, et al. Undiagnosed hypertension in a rural district in Bangladesh: the Bangladesh population-based diabetes and eye study (BPDES). J Hum Hypertens 2016;30:252-9.

15 Khanam MA, Lindeboom W, Razzaque A, et al. Undiagnosed and uncontrolled hypertension among the adults in rural Bangladesh: findings from a community-based study. J Hypertens 2015;33:2399-406. 
16 National Institute of Population Research and Training. NIPORT/ Bangladesh, Mitra and Associates/Bangladesh, and ICF international. Bangladesh demographic and health survey 2011. Dhaka, Bangladesh: NIPORT, Mitra and Associates, and ICF International, 2013. http://dhsprogram.com/publications/publication-fr265-dhsfinal-reports.cfm\#sthash.ipbFeOwm.dpuf

17 Chowdhury MAB, Uddin MJ, Haque MR, et al. Hypertension among adults in Bangladesh: evidence from a national cross-sectional survey. BMC Cardiovasc Disord 2016;16:22.

18 Rahman M, Zaman MM, Islam JY, et al. Prevalence, treatment patterns, and risk factors of hypertension and pre-hypertension among Bangladeshi adults. J Hum Hypertens 2018;32:334-48.

19 Khanam R, Baqui AH, Syed MIM, et al. Can facility delivery reduce the risk of intrapartum complications-related perinatal mortality? findings from a cohort study. J Glob Health 2018;8:010408.

20 Khanam R, Ahmed S, Creanga AA, et al. Antepartum complications and perinatal mortality in rural Bangladesh. BMC Pregnancy Childbirth 2017;17:81.

21 Khanam R, Creanga AA, Koffi AK, et al. Patterns and determinants of care-seeking for antepartum and intrapartum complications in rural Bangladesh: results from a cohort study. PLoS One 2016;11:e0167814.

22 Baqui AH, Khanam R, Rahman MS, et al. Understanding biological mechanisms underlying adverse birth outcomes in developing countries: protocol for a prospective cohort (AMANHI bio-banking) study. J Glob Health 2017;7:021202.

23 Rahman S, Choudhury AA, Khanam R, et al. Effect of a package of integrated demand- and supply-side interventions on facility delivery rates in rural Bangladesh: implications for large-scale programs. PLoS One 2017;12:e0186182.

24 Riley L, Guthold R, Cowan M, et al. The world Health organization stepwise approach to noncommunicable disease risk-factor surveillance: methods, challenges, and opportunities. Am J Public Health 2016;106:74-8.

25 Bonita R, Winkelmann R, Douglas KA. The WHO Stepwise Approach to Surveillance (Steps) of Non-Communicable Disease Risk Factors. In: McQueen DV, Puska P, eds. Global behavioral risk factor surveillance. Boston, MA: Springer US, 2003: 9-22.

26 Chalmers J, MacMahon S, Mancia G, et al. 1999 World health Organization-International Society of hypertension guidelines for the management of hypertension. guidelines Sub-committee of the world Health organization. Clin Exp Hypertens 1999;21:1009-60.

27 Chobanian AV, Bakris GL, Black HR, et al. The seventh report of the joint National Committee on prevention, detection, evaluation, and treatment of high blood pressure: the JNC 7 report. JAMA 2003;289:2560-72.

28 Islam JY, Zaman MM, Haq SA, et al. Epidemiology of hypertension among Bangladeshi adults using the 2017 ACC/AHA hypertension clinical practice guidelines and joint National Committee 7 guidelines. $J$ Hum Hypertens 2018;32:668-80.

29 Quan H, Chen G, Tu K, et al. Outcomes among 3.5 million newly diagnosed hypertensive Canadians. Can J Cardiol 2013;29:592-7.

30 Expert Consultation WHO. Appropriate body-mass index for Asian populations and its implications for policy and intervention strategies. Lancet 2004;363:157-63.

31 Filmer D, Pritchett L. Estimating wealth effects without expenditure data - or tears: An application of educational enrollment in states of India. The World Bank, 1998.

32 Rutstein SO JK. The DHS wealth index. DHS comparative reports No. 6. Calverton, Maryland: ORC Macro, 2004

33 World Health Organization. Step manual. The who stepwise approach to chronic disease risk factor surveillance. Geneva, Switzerland, 2008.

34 Forde C. Scoring the International physical activity questionnaire (IPAQ). Trinity College Dublin, the University of Dublin. Available: https://ugc.futurelearn.com/uploads/files/bc/c5/bcc53b14-ec1e4d90-88e3-1568682f32ae/IPAQ_PDF.pdf [Accessed on 23 Mar 2019].

35 Khanam MA, Lindeboom W, Razzaque A, et al. Prevalence and determinants of pre-hypertension and hypertension among the adults in rural Bangladesh: findings from a community-based study. BMC Public Health 2015;15:203.

36 Kaur P, Rao SR, Radhakrishnan E, et al. Prevalence, awareness, treatment, control and risk factors for hypertension in a rural population in South India. Int J Public Health 2012;57:87-94.

37 Krishnadath ISK, Jaddoe VWV, Nahar-van Venrooij LM, et al. Ethnic differences in prevalence and risk factors for hypertension in the Suriname health study: a cross sectional population study. Popul Health Metr 2016;14:33.

38 Ibrahim MM, Damasceno A. Hypertension in developing countries. Lancet 2012;380:611-9.

39 Kayima J, Wanyenze RK, Katamba A, et al. Hypertension awareness, treatment and control in Africa: a systematic review. BMC CardiovasC Disord 2013;13:54

40 Hirani V, Zaninotto P, Primatesta P. Generalised and abdominal obesity and risk of diabetes, hypertension and hypertensiondiabetes co-morbidity in England. Public Health Nutr 2008;11:521-7.

41 Yalcin BM, Sahin EM, Yalcin E. Which anthropometric measurements is most closely related to elevated blood pressure? Fam Pract 2005;22:541-7.

42 Kibria GMA, Swasey K, Choudhury A, et al. The new 2017 ACC/AHA guideline for classification of hypertension: changes in prevalence of hypertension among adults in Bangladesh. J Hum Hypertens 2018:32:608-16.

43 Leng B, Jin Y, Li G, et al. Socioeconomic status and hypertension: a meta-analysis. Journal of hypertension 2015;33:221-9.

44 Diaz KM, Booth JN, Seals SR, et al. Physical activity and incident hypertension in African Americans: the Jackson heart study. Hypertension 2017;69:421-7.

45 Diaz KM, Shimbo D. Physical activity and the prevention of hypertension. Curr Hypertens Rep 2013;15:659-68.

46 Zaman MM, Bhuiyan MR, Karim MN, et al. Clustering of noncommunicable diseases risk factors in Bangladeshi adults: an analysis of steps survey 2013. BMC Public Health 2015;15:659.

47 Noubiap JJN, Bigna JJR, Nansseu JRN. Low sodium and high potassium intake for cardiovascular prevention: evidence revisited with emphasis on challenges in sub-Saharan Africa. J Clin Hypertens 2015;17:81-3.

48 Krupp D, Esche J, Mensink G, et al. Dietary acid load and potassium intake associate with blood pressure and hypertension prevalence in a representative sample of the German adult population. Nutrients 2018;10:103.

49 Martínez-Pineda M, Yagüe-Ruiz C, Caverni-Muñoz A, et al. Reduction of potassium content of green bean pods and chard by culinary processing. tools for chronic kidney disease. Nefrología 2016:36:427-32.

$50 \mathrm{FJ} \mathrm{H}$, MacGregor GA. Blood pressure is the most important cause of death and disability in the world. Eur Heart $J$ 2007;9:B23-8.

51 Lawes CMM, Vander Hoorn S, Rodgers A, et al. Global burden of blood-pressure-related disease, 2001. Lancet 2008;371:1513-8.

52 Lewington S, Clarke R, Qizilbash N, et al. Age-specific relevance of usual blood pressure to vascular mortality: a meta-analysis of individual data for one million adults in 61 prospective studies. Lancet 2002;360:1903-13.

53 Kishore SP, Heller DJ, Vasan A. Beyond hypertension: integrated cardiovascular care as a path to comprehensive primary care. Bull World Health Organ 2018;96:219-21. 